\title{
Educação e Tecnologias aplicadas ao ensino profissional e tecnológico: relato de experiência docente no Mestrado ProfEPT
}

Rosana Ferrareto Lourenço Rodrigues, Instituto Federal de Educação, Ciência e Tecnologia de São Paulo, Câmpus São João da Boa Vista, rosanaferrareto@,ifsp.edu.br, https://orcid.org/0000-0003-0332-4548

Nemésio Freitas Duarte Filho, Instituto Federal de Educação, Ciência e Tecnologia de São Paulo, Câmpus Sertãozinho, nemesio@ifsp.edu.br https://orcid.org/0000-0001-5084-3733

RESUMO: A relação entre Educação e Tecnologias é um tema caro ao desenvolvimento curricular na Educação Profissional e Tecnológica (EPT), pois promove a formação integral e integrada do educando. No contexto da EPT, elaborar e aplicar projetos de ensino, com utilização de tecnologias, são objetivos de disciplinas na interface Educação/Tecnologias. Este artigo relata a experiência de dois docentes de um Instituto Federal, no Programa de Mestrado Profissional em EPT (ProfEPT). São descritos planejamento, execução e avaliação do curso na modalidade $\mathrm{EaD}$, utilizando a plataforma Moodle, à luz de princípios do Design Instrucional. Como resultado, apresenta-se a aplicação da disciplina como prática interdisciplinar para a formação do mestrando, preparando-o para a elaboração de produtos educacionais, demanda do ProfEPT.

Palavras-chaves: educação e tecnologias, Educação Profissional e Tecnológica, EaD e Design Instrucional.

\section{Education and Technologies applied to Professional and Technological Education: a report on a teaching experience in the ProfEPT Master's Program}

\begin{abstract}
Education interfaced with Technology is a key point to the curriculum development in Professional and Technological Education (EPT) as it promotes an integrated comprehensive student training. In such a context, elaborating and applying teaching projects, using technologies, are the aims of disciplines in the Education/ Technologies interface. This article reports the experience of two professors from a Federal Institute, in the Professional Master's Program in EPT (ProfEPT). The course's Instructional Design, offered on Moodle, is thoroughly described in its three stages: Planning, Implementation and Evaluation. As a result, we report the discipline applied as an interdisciplinary practice towards the education of Master's Degree students for the development of educational products, which is a demand of ProfEPT.
\end{abstract}

Keywords: education and technologies, Professional and Technological Education, distance education and Instructional Design.

\section{Introdução}

A Educação Profissional e Tecnológica (EPT), cujo princípio se embasa na oferta de cursos, currículos e programas direcionados ao mundo do trabalho, configura-se como importante canal de acesso à qualificação profissional e está incluída na pauta das políticas públicas do Governo Federal ${ }^{1}$. Diante da importância do ensino profissional para o desenvolvimento do país, diversas iniciativas surgiram com foco em impulsionar a EPT nas escolas e instituições de ensino.

\footnotetext{
${ }^{1}$ http://portal.mec.gov.br/cursos-da-ept
} 
O Mestrado Profissional em Educação Profissional e Tecnológica em Rede Nacional (ProfEPT) surgiu tendo como objetivo proporcionar maior formação em educação profissional e tecnológica aos profissionais da Rede Federal de Educação Profissional, Científica e Tecnológica (RFEPCT), visando tanto a produção de conhecimento como o desenvolvimento de produtos, por meio da realização de pesquisas que integrem os saberes inerentes ao mundo do trabalho e ao conhecimento sistematizado.

Dentro do ProfEPT, existe uma linha de pesquisa denominada "Práticas Educativas em EPT", cujo foco é trabalhar os fundamentos das práticas educativas e do desenvolvimento curricular na EPT, em suas diversas formas de oferta, com foco nas estratégias transversais e interdisciplinares, que possibilitem formação integral e significativa do estudante, sustentados no trabalho como princípio educativo e na pesquisa como princípio pedagógico, em espaços formais e não formais. Isso possibilita aos egressos a capacidade para a criação de soluções e produtos educacionais que possam contribuir para a melhoria do ensino ${ }^{2}$. Uma das disciplinas eletivas do ProfEPT, que apoia a construção de produtos educacionais com base na utilização de diferentes tecnologias, é a disciplina de "Educação e Tecnologias". Tal componente curricular tem por objetivo mostrar o papel da educação na sociedade contemporânea em suas relações com as tecnologias digitais com aplicação no ensino profissional e tecnológico, engajando e motivando os futuros profissionais na utilização de tecnologias diversificadas com foco na formação integrativa e omnilateral ${ }^{3}$.

Nesse contexto, o objetivo deste trabalho é descrever a experiência da docência compartilhada, entre um professor de Informática e uma professora de Linguística, da disciplina Educação e Tecnologias no Mestrado ProfEPT em um câmpus do Instituto Federal de São Paulo. No relato aqui apresentado, são descritos o desenho e a oferta do curso, bem como reflexões advindas da avaliação dos professores sobre o processo.

Ofertado na modalidade $\mathrm{EaD}$, o curso foi desenvolvido e aplicado na plataforma Moodle à luz de princípios do Design Instrucional (DI). As ferramentas desse ambiente virtual de aprendizagem (AVA) permitem o uso de atividades teóricas e práticas, tais como textos, vídeos, questionários, tarefas, fóruns, glossário e wiki, para $\mathrm{o}$ desenvolvimento de habilidades de leitura, interpretação e produção textuais de vários gêneros, tais como artigos, resenhas, entrevistas, relatos, entre outros. O contato com esses gêneros possibilita a formação dos discentes para o uso de tecnologias em processos educativos. $\mathrm{O}$ caráter inovador da abordagem metodológica está na integração entre o AVA e ferramentas tecnológicas externas, tais como aplicativos e programas de produção de mídias audiovisuais, tais como vídeos animados, flashcards, mapas mentais, murais online colaborativos - um conjunto integrado de ferramentas para a produção de conteúdo na construção de conhecimento durante o percurso de aprendizagem.

Este artigo apresenta, na fundamentação teórica, considerações sobre a formação omnilateral na EPT, o papel da tecnologia nos processos educativos, o uso do DI em cursos EaD. Na metodologia, são descritas as etapas de planejamento, execução e avaliação da disciplina Educação e Tecnologias no Mestrado ProfEPT, apresentando-se exemplos de aplicação das atividades no Moodle, com o uso de ferramentas tecnológicas integradas. Como resultados, são apresentados os documentos de DI elaborados para o processo de oferta da disciplina e, nas considerações finais, são relatadas as reflexões dos docentes sobre o processo da disciplina.

\section{Fundamentação Teórica}

\footnotetext{
${ }^{2} \mathrm{https}$ ://profept.ifes.edu.br/regulamentoprofept

${ }^{3}$ https://profept.ifes.edu.br/componentescurriculares 
A EPT, em sua concepção, busca preparar os alunos não somente para o mundo de trabalho, mas também para a formação de cidadãos críticos e reflexivos (Ramos, 2010). A ideia é promover o aprendizado da técnica, e, ao mesmo tempo, garantir a apropriação de conhecimentos gerais e propedêuticos, que propiciem ao indivíduo a opção de escolher e construir caminhos para a produção da vida, a partir de seu trabalho. Considerar o trabalho como princípio educativo é partir do pressuposto de que o ser humano produz sua realidade, podendo apropriar-se dela e transformá-la, tornando-o sujeito de sua história e realidade (Ramos, 2008).

Atualmente, muitas instituições de ensino já conseguem inserir os fundamentos da EPT em seus currículos escolares (Ciavatta, 2005). Porém, seu conteúdo é bastante abstrato, vasto e diversificado, sendo, na maioria das vezes, ensinado de forma unicamente expositiva. Essa falta de interação e colaboração entre alunos, professores e conteúdos da EPT pode causar desinteresse e desmotivação na aprendizagem. $\mathrm{O}$ aluno não se enxerga naquilo que está sendo ensinado, não consegue associar o conhecimento politécnico e omnilateral ao seu cotidiano nem refletir de que forma aquilo pode influir em sua vida. Para Andrade, Miranda e Varino (2015), se o conteúdo não estabelecer comunicação e significado ao indivíduo, será apenas depositado para um fim imediato, ao invés de contribuir para a formação do saber do cidadão estudante.

Surge, então, a necessidade da renovação das práticas de ensino para além da metodologia tradicional, com o objetivo de promover um processo de ensinoaprendizagem mais interessante, flexível, integrativo e colaborativo, relacionado ao fortalecimento do pensar crítico, criativo, com uso e entendimento da tecnologia comprometida com o social (Moura, 2007; 2014). Dentre as novas formas de ensinar e aprender, estão a tecnologia e a integração dos recursos usados com a participação efetiva de alunos e docentes. Assim, a educação é vista como um dos meios capazes de proporcionar à classe trabalhadora um saber que seja instrumento de luta, a fim de que possa, de forma consciente, renascer enquanto homem e com ele uma nova escola (Severo, 2014).

A tecnologia é uma ferramenta de mediação no processo de ensino-aprendizagem. As tecnologias da informação e comunicação não só nos proporcionaram novas formas de nos relacionar com os outros, mas nos possibilitaram um saber democrático devido à sua ubiquidade. Nesse contexto, os ambientes virtuais facilitaram a modalidade de ensino a distância, devido a revoluções tecnológicas, como a internet, o lançamento de aparelhos eletrônicos, as lógicas e linguagens, o que fomentou novas formas de consumir e produzir conhecimento (Filatro, 2010).

Se a tecnologia vem para enriquecer e facilitar o processo de ensino-aprendizagem nas práticas profissionais, nas relações humanas, na pesquisa e se aprendizes adultos são autônomos para utilizá-la das formas mais criativas possíveis, o desafio que se impõe é como torná-la uma ferramenta educacional mais eficaz, como planejar a utilização para fins educacionais (Filatro, 2010). Além disso, o crescimento da $\mathrm{EaD}$ requer planejar, desenvolver e implementar cursos para o aprendizado eletrônico. Suas práticas mais recentes e modernas estão pautadas no conceito de DI, que é a pedagogia do AVA. O processo de DI consiste no planejamento, implementação e avaliação de uma situação de ensino-aprendizagem, concretizada por meio de um curso.

A prática em DI não pode prescindir das teorias pedagógicas: o foco da sua atuação está na convergência que consegue realizar entre as tecnologias, os conteúdos e o contexto em que ocorrerá a ação educativa com uma finalidade única e exclusiva: garantir a melhor qualidade de aprendizagem aos estudantes (Kenski, 2015). Na implantação de um curso a distância, o planejamento na gestão do projeto instrucional é imprescindível. O planejamento é o fio-condutor da $\mathrm{EaD}$, pois nessa modalidade de 
ensino-aprendizagem, o estudante é o centro do processo, obrigando a um planejamento detalhado das etapas de pré-produção, produção e pós-produção do curso (Lenzi; Spanhol, 2011).

Um dos recursos de DI na fase de planejamento é o mapa de atividades, utilizado para a descrição de todas as atividades, teóricas ou práticas, bem como para a indicação das ferramentas do ambiente virtual a serem empregadas e as avaliações previstas. Esse recurso é o fio condutor da execução do curso. No processo entre planejamento, execução e avaliação, o DI tem como princípio o desenvolvimento de competências complexas e o estímulo a atitudes autônomas, tais como o pensamento analítico/crítico, a criatividade, a flexibilidade e a capacidade de gerenciar informações. É uma área que une educação, tecnologia, comunicação e gestão em um único campo do conhecimento (Filatro, 2008)

\section{Metodologia}

Considerando que a oferta da disciplina Educação e Tecnologias, objeto de estudo deste trabalho, ocorreu na modalidade $\mathrm{EaD}$, a metodologia consiste na modelagem do projeto de curso a partir dos estágios: planejamento, execução, avaliação e melhorias. Baseou-se nos princípios do DI no modelo ADDIE (Analysis, Design, Development, Implementation and Evaluation) (Figura 1), uma estrutura para projetos instrucionais compostos pelos processos de análise, design, desenvolvimento, implementação e avaliação (Filatro, 2008).

Figura 1 - Concepção e implementação da disciplina no modelo ADDIE

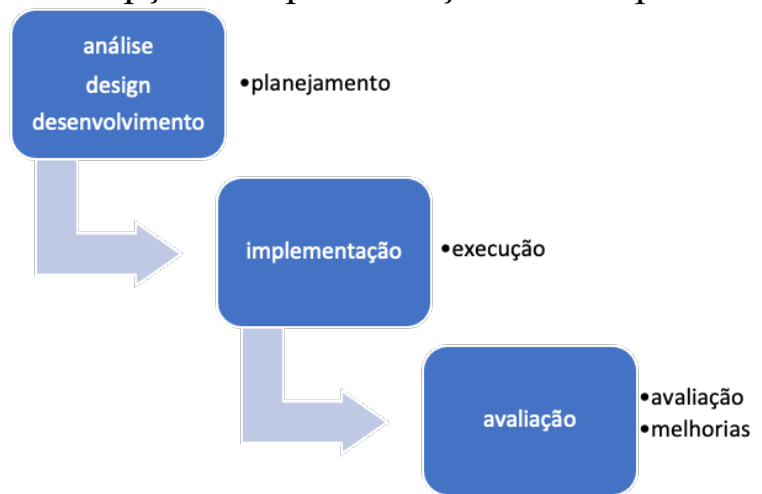

Fonte: Elaboração dos autores, baseado em Filatro (2008)

Para o estágio de planejamento, realizou-se, a partir da análise da ementa ${ }^{4}$ e referências bibliográficas do curso, a seleção de materiais teóricos e práticos (textos, ferramentas digitais, como vídeos e softwares/apps gratuitos) adequada para o design do curso, seguida, no desenvolvimento, pela construção do cronograma de aulas (ancorado no conceito de mapa de atividades do DI) e a alimentação do conteúdo no AVA (Moodle). De acordo com Filatro (2008), o mapa de atividades é um recurso que possibilita a visão geral de cada unidade de aprendizagem, com o detalhamento das atividades teóricas e práticas, a partir dos objetivos, conteúdos, ferramentas e avaliações. O objetivo geral do curso é proporcionar uma reflexão sobre as TIC e suas implicações no processo de expansão, manutenção e transformação na cultura, bem como sua capacidade de reconfigurar as relações que circundam o processo de ensino-aprendizagem em suas múltiplas faces.

\footnotetext{
${ }^{4} \mathrm{https} / / /$ ifce.edu.br/fortaleza/profept/disciplinas 
O conteúdo programático foi organizado em dez semanas, compostas por atividades teóricas (texto para leitura e vídeo) e por uma atividade prática com o uso de uma ferramenta digital. Para o design do Moodle, organizou-se cada aba semanal explicitando os objetivos e distribuindo as atividades práticas, integrando as ferramentas do próprio AVA e os demais softwares/vídeos. Definiu-se, quanto às atividades avaliativas, que haveria uma atividade prática semanal e uma atividade final cumulativa das atividades semanais.

Para a execução do curso, a docência foi compartilhada entre dois professores do programa, uma linguista e um cientista da computação. Estabeleceu-se que cada um ficaria responsável por cinco semanas de implementação do curso, acompanhando o processo de aprendizagem, respondendo aos fóruns e avaliando as atividades semanais. Nas semanas 1 a 5, foram utilizadas: uma ferramenta web de geração de nuvem de palavras; uma ferramenta wiki e dois envios de tarefas do próprio Moodle; e uma atividade utilizando o mural Padlet. Nas semanas 6 a 10, foram utilizadas: duas ferramentas do Moodle, o glossário e o envio de tarefas; e três ferramentas digitais para a produção de flashcards, mapa mental e vídeo animação. Para todas as atividades, foram disponibilizados tutoriais de forma a auxiliar os alunos na utilização e interação com as ferramentas. As atividades práticas consistiram em usar a ferramenta para interpretar o texto e compreender o conteúdo do vídeo e, assim, aprender os conceitos sobre as atividades teóricas, a partir do desenvolvimento de habilidades como: síntese, análise, aquisição de vocabulário, diagramação visual de ideia, criação de conteúdo.

A última etapa se baseou na avaliação e melhorias de todo o processo de planejamento e condução da disciplina. Os modelos de avaliação adotados foram os de avaliação formativa, para as dez atividades práticas semanais, com o uso de diferentes ferramentas; e somativa, na avaliação final, a partir da elaboração de um portfólio.

O maior mérito da avaliação formativa é a ajuda ao aluno em relação à aprendizagem do conteúdo e dos comportamentos em cada unidade de aprendizagem (Bloom; Hastings; Madaus, 1971). Por ser processual e continuada, exige uma organização do currículo, mas permite que o professor adapte as tarefas, faça alterações para melhor adequação destas ao conteúdo programático. Ao acompanhar integralmente o processo de ensino-aprendizagem, é dinâmica e permite a personalização da devolutiva ao aluno, para verificar se está atingindo gradativamente os objetivos previstos por meio de conceitos, habilidades e atitudes. Não envolve unicamente a atribuição de notas, mas a percepção, aos alunos e professores, dos pontos positivos e negativos do processo educativo. A avaliação formativa permitiu devolutivas semanais sobre cada uma das dez unidades de ensino.

Junto à avaliação formativa, utilizamos a avaliação somativa. Segundo Shepherd e Godwin (2004), a avaliação somativa é classificatória e, por ser instrumento de certificação, tem função social. Proporciona uma pontuação a partir dos conhecimentos e habilidades adquiridas, atribui uma nota definitiva, tendo por base os níveis de aproveitamento estabelecidos. Pode ser um teste, prova ou exame. Como resultado globalizante do desenvolvimento dos conhecimentos e competências, optamos por eleger como instrumento de avaliação final o portfólio, um registro final do ciclo de ensino, contendo todas as unidades. A forma como foi construído o portfólio - contendo a descrição das atividades semanais, com um texto de reflexão, chamado diário de aprendizagem, e a apresentação do aluno e do curso, no texto de introdução - permite uma avaliação global, que deve ser orientada por critérios de correção que atendam ao objetivo do curso. Por isso, criamos uma matriz de avaliação com a descrição dos critérios e seus respectivos pesos para a composição da nota. Além disso, oferecemos aos alunos um modelo do documento a ser preenchido e um exemplo de um portfólio já preenchido 
para que pudessem visualizar o que se esperava que cumprissem para atingir o objetivo da atividade avaliativa.

Além das atividades avaliativas formativas e somativa, ao final da disciplina, os docentes se reuniram expondo fatos e situações positivas e negativas vivenciadas ao longo do curso. Para também identificar as percepções dos alunos concluintes sobre o curso, foi elaborado um questionário no Google $\mathrm{Forms}^{5}$, com questões de múltipla escolha e dissertativas. Todas essas informações foram sintetizadas, destacando-se pontos de melhorias (mudanças e adaptações) e pontos fortes (acertos e asserções).

\section{Resultados e Discussão}

Os documentos que nortearam o planejamento, a execução e a avaliação da disciplina Educação e Tecnologias perfazem: a programação em formato de mapa de atividades; a organização dessas na plataforma Moodle; as devolutivas semanais; o projeto final como instrumentos de avaliação; e um relato da percepção docente e discente ao final do curso. O mapa de atividades (Figura 2) apresenta o tema desenvolvido semanalmente, os objetivos de aprendizagem e as atividades teóricas e práticas.

Figura 2 - Programação da disciplina em um mapa de atividades ${ }^{6}$

\begin{tabular}{|c|l|l|l|l|}
\hline Semana & \multicolumn{1}{|c|}{ Tema } & \multicolumn{1}{|c|}{ Objetivos } & $\begin{array}{l}\text { Atividades } \\
\text { teóricas }\end{array}$ & Atividades práticas \\
\hline 1 & $\begin{array}{l}\text { Histórico/evolução } \\
\text { das tecnologias na } \\
\text { educação }\end{array}$ & $\begin{array}{l}\text { Motivar a leitura para extração de dados } \\
\text { e facilitar a visualização de informações } \\
\text { ao sintetizar/resumir um tema } \\
\text { específico. }\end{array}$ & $\begin{array}{l}\text { Artigos } \\
\text { científicos e } \\
\text { didáticos } \\
\text { Vídeos no } \\
\text { YouTube }\end{array}$ & $\begin{array}{l}\text { Nuvem de palavras } \\
\text { https://www.wordclo } \\
\text { uds.com }\end{array}$ \\
\hline$\ldots$ & $\ldots$ & $\ldots$ & $\ldots$ & $\ldots$ \\
\hline 10 & $\begin{array}{l}\text { O Trabalho } \\
\text { Pedagógico } \\
\text { Online }\end{array}$ & $\begin{array}{l}\text { Organizar um conceito narrativamente } \\
\text { de forma lúdica e engajadora. }\end{array}$ & $\begin{array}{l}\text { Artigos } \\
\text { científicos e } \\
\text { didáticos } \\
\text { Vídeos no } \\
\text { YouTube }\end{array}$ & $\begin{array}{l}\text { Powttps://www.powtoon } \\
\text { com }\end{array}$ \\
\hline
\end{tabular}

Fonte: Elaboração dos autores com base em Filatro (2008)

Cada atividade teórica é composta de dois ou três vídeos e artigos, selecionados pelos docentes, em consonância com o tema da semana. A atividade prática consiste no uso de informações do material teórico, ressignificadas para a prática educativa em contexto de EPT, a partir de reflexão e criação dos alunos com o uso de uma ferramenta. Todas as semanas, conforme descritas no mapa de atividades, foram organizadas no Moodle (Figura 3) a partir das seções do mapa de atividades.

Figura 3 - Exemplo de semana de atividades no Moodle

\footnotetext{
${ }^{5}$ Formulário: https://bit.ly/3yFwmG3

${ }^{6}$ Mapa de Atividades: https://bit.ly/3yAp0DI 


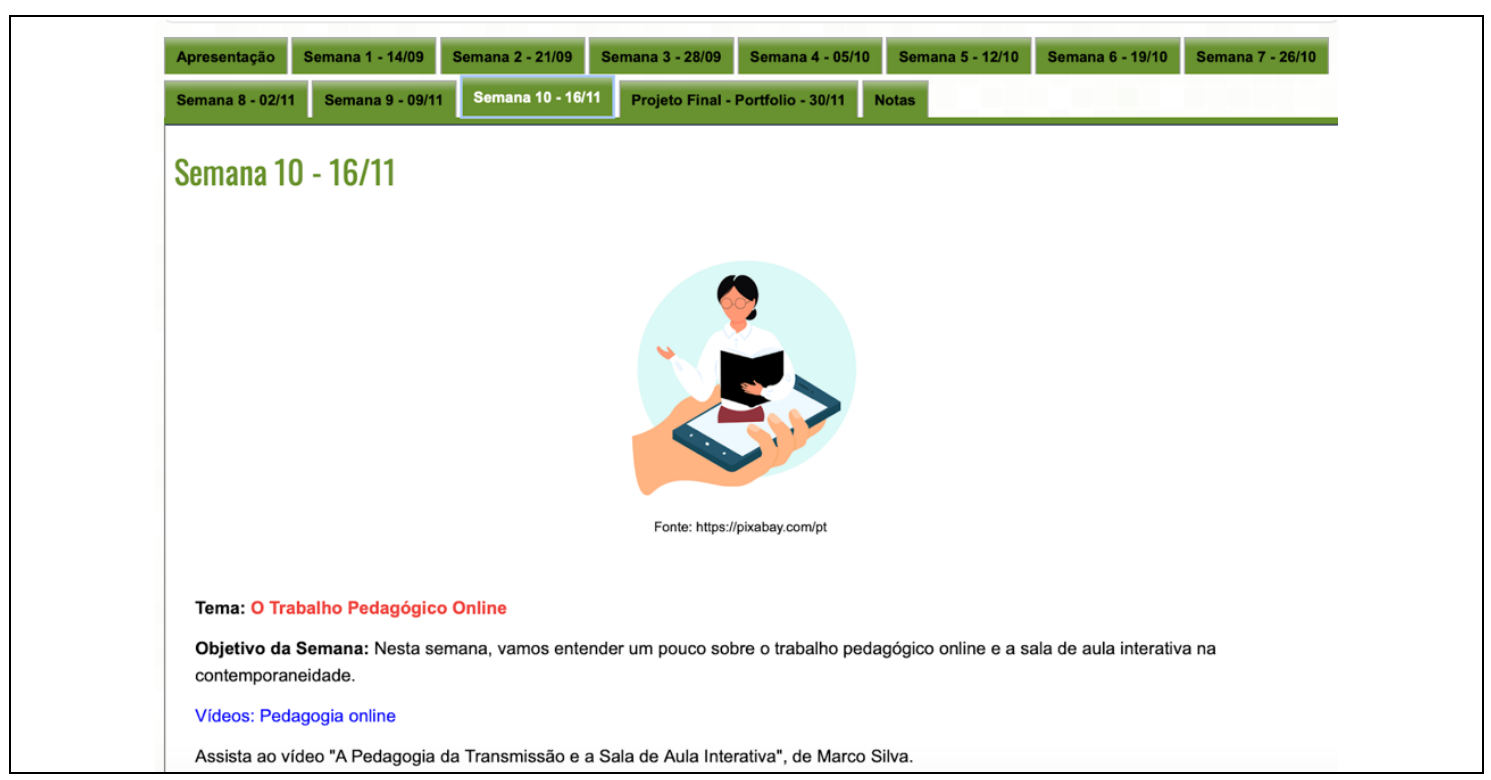

Fonte: Elaboração dos autores em https://ava.cefor.ifes.edu.br

A pertinência das atividades para o desenvolvimento do conteúdo e atendimento do objetivo com o uso da ferramenta como exercício foi considerada em cada proposta (Figura 4).

Figura 4 - Atividade com a ferramenta de vídeo animação Powtoon

Nesta semana, falamos sobre os processos de interação e cocriação, então nada mais natural do que fazer uma atividade que permita exercitarmos esses dois processos.

A atividade que iremos realizar nesta semana será a criação de uma pequena animação, utilizando o aplicativo Powtoon. Sigam os seguintes passos: 1 - Definir uma temática. O tema deverá ser algum conceito ou ideia visto ao longo dessa disciplina. Fica a critério de cada aluno; 2 - Tempo de duração do vídeo: Até 3 minutos; 3 - Criar um pequeno roteiro para facilitar a construção de sua animação; 4 - Criar uma conta para acessar o Powtoon; 5 - Criar sua animação e depois de pronta ela deve ser salva no youtube; 6 - Após a animação ser salva no youtube, você deve compartilhar o link aqui no fórum, assim todos poderão acessar e compartilhar o conhecimento adquirido.

IMPORTANTE: Esta atividade é avaliativa e vale 4 pontos. Prazo: 23 de novembro, segunda, $23 \mathrm{~h} 55$. Responda a este fórum com o título e link do seu Powtoon.

Veja uma resposta a seguir, como exemplo (o exemplo é ilustrativo. Você deve atender ao tema da proposta e o tempo de duração estipulado. O vídeo Powtoon deve estar disponível no YouTube). Título do meu Powtoon: [ ] Link para meu Powtoon: $<>$

Fonte: Elaboração dos autores em https://ava.cefor.ifes.edu.br

A utilização de diferentes ferramentas ao longo das atividades semanais pode proporcionar maior conhecimento e experiências para o aluno da disciplina, futuro profissional da EPT. Ao longo de um processo de ensino-aprendizagem, ele aprende a promover a integração e motivação frente às práticas educacionais, a partir do uso integrado de ferramentas colaborativas, tais como: um sistema de geração de nuvem de palavras, que possibilita visualizar conceitos de conteúdos; a construção de uma wiki, que pode ser utilizada em diferentes produtos educacionais, permitindo colaboração dinâmica e construtiva; o fórum, que permite o compartilhamento de ideias frente a uma temática específica, ajudando na rápida visualização e respostas dos docentes e alunos; o Padlet, mural interativo para demonstração de conteúdos e ideias, permitindo comentários e reações; o glossário, para ajudar na organização e sistematização de palavras frente a um componente educacional; os flashcards, como um método rápido e de fácil memorização de novos conceitos; uma sequência didática, utilizada para organizar o trabalho V. $19 \mathrm{~N}^{\mathrm{o}} 1$, julho, 2021 DOI: https://doi.org/10.22456/1679-1916.118413 RENOTE 
pedagógico; o mapa mental, utilizado como forma de diagramação visual de conceitos organizados logicamente; o Powtoon, que permite a criação de vídeo animação com conteúdos de ensino de forma simplificada, motivando a utilização e compartilhamento por parte dos alunos.

No que diz respeito à avaliação, os docentes ofereceram devolutivas semanais, via fórum ou mensagem por e-mail e no Moodle (Figura 5), a partir das quais puderam dar atenção à motivação dos alunos, à regularidade do seu esforço, à sua forma de abordar as tarefas e às estratégias de resolução de problemas. Esse tipo de devolutiva da avaliação formativa contribui para melhorar a motivação e autoestima do aluno. As mensagens devolutivas inclusive incluíam menção à atividade seguinte, mostrando a relação entre elas, incentivando os alunos a dar continuidade à construção do conhecimento.

\section{Figura 5 - Devolutiva do "Mapa Conceitual" (Avaliação Formativa)}

O objetivo da atividade foi refletir sobre o apoio da tecnologia a mediação pedagógica e aprender sobre mapas mentais e como utilizá-los enquanto ferramenta para ilustrar ideias e conceitos. O aplicativo usado foi o Coggle (https://coggle.it/). Foram disponibilizados exemplos de mapas criados por alunos de turmas anteriores. A tarefa era escolher um projeto de curso técnico, de uma instituição de ensino, e procurar nele como o uso das tecnologias pode apoiar o processo de mediação pedagógica. A partir disso, vocês construíram o Mapa Mental definindo como a mediação pedagógica apoiada pelo uso de tecnologias digitais aparece no projeto do curso. Cada aluno gerou uma imagem (JPG ou PNG) e enviou como tarefa. A atividade é avaliativa e vale 4 pontos. O prazo foi 16 de novembro, segunda, 23h55. Estes são os critérios de avaliação (As notas foram postadas no envio de tarefa): Atendimento à atividade (prazo e formato, uso do app) - 1,0; Adequação ao tema (PPC e uso de tecnologia/mediação pedagógica) - 1,5; Uso correto da língua portuguesa e clareza (escrita dos termos, boa organização dos termos de forma legível) $-1,5$.

Vejam a diversidade/pluralidade da EPT no resultado da atividade com mapa mental a partir da análise do tema mediação pedagógica/tecnologia nos PPCs: Os cursos cujos PPCs foram contemplados nos mapas são: EM Integrado em Informática; EM Integrado em Química; EM Integrado em Eletrônica; EM Integrado em Segurança do Trabalho; EM Integrado em Agropecuária; Técnico em Administração; Técnico em Automação Industrial; Técnico em Segurança do Trabalho - EJA; Técnico em Meio Ambiente. Das seguintes instituições: IFSP, IFPR, IFMG, IFRO, IFFAR, Centro Paula Souza. Os termos relacionados à tecnologia como mediação pedagógica que mais apareceram nos mapas foram: ambientes de aprendizagem (Moodle), softwares, apps, redes sociais, gêneros digitais (blog, chat, email etc), modalidade $\mathrm{EaD}$, uso de TIC; como metodologia e competências/habilidades em disciplinas gerais e em disciplinas técnicas específicas e em projetos. Os mapas ficaram visualmente bonitos, coloridos e alguns têm imagens, o que fica ainda mais interessante em termos de design. Reservem a imagem do mapa para inserir no portfólio após a Semana 10. Parabéns pelo excelente trabalho! Objetivo cumprido!

\section{Fonte: Elaboração dos autores}

A avaliação somativa, realizada a partir da elaboração do portfólio ${ }^{7}$, forneceu um resumo do conhecimento construído ao longo do curso. Ocorreu ao final da instrução, com a finalidade de verificar o que o aluno efetivamente aprendera, incluindo no portfólio os conteúdos mais relevantes e os objetivos mais amplos do período de instrução. $\mathrm{O}$ portfólio permitiu registrar, em um único documento, a trajetória dos alunos no curso, proporcionando a eles uma coleção de atividades úteis para a sua prática pedagógica e acadêmica. Para a verificação do processo de aprendizagem, criou-se uma matriz de avaliação ${ }^{8}$, com critérios e distribuição de notas.

\footnotetext{
${ }^{7}$ Portfólio: https://bit.ly/3bP5DwS

${ }^{8}$ Matriz de avaliacãa: https://bit.ly/2ScsnzP

V. $19 \mathrm{~N}^{\mathrm{o}} 1$, julho, 2021

DOI: https://doi.org/10.22456/1679-1916.118413 
As respostas do questionário sobre a percepção discente foram sintetizadas, possibilitando uma visão crítica/complementar dos participantes do curso. Destacaramse positivamente: layout e estrutura das informações visuais ao longo do curso; diversidade de ferramentas utilizadas nas atividades; rápido feedback dos docentes; motivação e engajamento dos docentes; e relacionamento do conteúdo da disciplina com os pilares da EPT. Apresentaram-se as seguintes críticas: tempo curto na execução do projeto final; ausência de aulas síncronas; falta de aspectos de inclusão e legendagem nos vídeos; e ausência de mais exemplos prontos, a partir dos modelos, nas atividades semanais.

Os docentes ponderaram sobre os seguintes aspectos do curso no contexto da EPT: aumento da interação e cooperação entre alunos; diferentes possibilidades de aprendizagem por meio da ludicidade e da interatividade de diferentes tecnologias; aumento da abrangência do ensino, numa perspectiva em que a aula pode se desdobrar em diferentes níveis de colaboração entre os alunos; e contribuição em relação à superação de dificuldades de aprendizagem.

Dessa forma, a análise permite concluir que a disciplina em questão, estruturada e organizada frente aos pilares da EPT, permite que diferentes potencialidades sejam exploradas na educação profissional, superando os desafios apontados em relação ao ensino tradicional.

\section{Conclusão}

Este artigo apresenta um relato de experiências sobre a concepção e aplicação de uma disciplina na modalidade EaD, na interface Educação/Tecnologias, no Mestrado Profissional ProfEPT em rede, a partir da docência compartilhada entre um professor de Informática e uma professora de Letras. Baseada nos princípios do DI e desenvolvida a partir do uso de ferramentas de um AVA, incorporadas a outras ferramentas tecnológicas de produção de conteúdo audiovisual, essa abordagem integrada e interdisciplinar contribui para a formação omnilateral dos estudantes para o mundo do trabalho em espaços formais e não formais de educação. Além disso, prepara os mestrandos para a elaboração de produtos educacionais, prática pertencente à pesquisa no ProfEPT. A oferta do curso na modalidade $\mathrm{EaD}$, composta de atividades teóricas sobre educação e tecnologias aliadas à instrução e uso de ferramentas tecnológicas nas atividades práticas, possibilita aos mestrandos em formação oportunidade de experienciar um percurso formativo dinâmico e interativo para a construção do conhecimento em meios online.

A percepção dos alunos, relatadas ao final do curso, demonstram a efetividade e objetividade da disciplina "Educação e Tecnologias" no contexto da EPT frente às diferentes tecnologias educacionais. As críticas/limitações identificadas são relevantes para que seja possível realizar um processo de melhoria e atualização contínua na disciplina. Destaca-se, contudo, breve justificativa com base nas limitações identificadas. Em relação ao tempo curto na execução do projeto final, vinculou-se ao fato de o cronograma seguir o calendário nacional do programa ProfEPT, no caso, 10 semanas. Não houve aulas síncronas, pois uma das orientações do programa ProfEPT é que as disciplinas EaD tenham apenas aulas gravadas, uma vez que é cursada por alunos de diferentes instituições/lugares com diferentes horários na grade curricular. Houve de fato uma carência de elementos de inserção cognitiva assistiva, uma vez que no grupo não havia alunos com necessidades específicas. Ressalta-se, porém, que esses elementos de inclusão já foram adicionados e implementados em uma turma vigente. Sobre os exemplos de atividades semanais, foram disponibilizados alguns exemplos genéricos de forma que os alunos pudessem usar a criatividade para resoluções diferentes das atividades. 
Como trabalhos futuros, os autores idealizam realizar: atualização e inclusão de novas tecnologias educacionais, de acordo com a evolução das tecnologias; inclusão de elementos de acessibilidade para deficientes auditivos e visuais, tais como áudio descrição, legendagem, entre outros; e compartilhamento e colaboração dos elementos da disciplina com outros docentes do programa ProfEPT, buscando contribuições e troca de experiências.

\section{Referências}

ANDRADE, A. B.; JESUS MIRANDA; N. C.; VARINO, D. F. C. Novas abordagens no ensino das Ciências Humanas: a premência de diversificar linguagens no labor docente com Geografia e História. Educação (UFSM), 40(1), p. 215-228, 2015.

BLOOM, B. S.; HASTINGS, J. T; MADAUS, G. Handbook on formative and summative evaluation of student learning. New York: McGraw-Hill Book Company. Trad.: Manual de avaliação formativa e somativa do aprendizado escolar. São Paulo: Livraria Pioneira Editora, 1971.

CIAVATTA, M. A formação integrada à escola e o trabalho como lugares de memória e de identidade. Revista Trabalho Necessário, 3(3), 2005.

FILATRO, A. Design Instrucional contextualizado: educação e tecnologia. 3. ed. São Paulo: Editora Senac São Paulo, 2010.

FILATRO, A. Design Instrucional na Prática. São Paulo: Pearson Education do Brasil, 2008.

KENSKI, V. M. Design Instrucional para cursos online. São Paulo: SENAC São Paulo, 2015.

LENZI, G. K. S.; SPANHOL, F. J. Gestão de projetos em Educação a Distância. RENOTE, 9(2), 2011.

MOURA, D. H. Trabalho e formação docente na educação profissional [recurso eletrônico]. Curitiba : Instituto Federal do Paraná, 2014. Coleção formação pedagógica; v. 3. Disponível em: $<$ https://curitiba.ifpr.edu.br/wp-content/uploads/2016/05/Trabalhoe-Formação-Docente.pdf>. Acesso em: 19 jul. 2021.

MOURA, D. H. Educação básica e educação profissional e tecnológica: dualidade histórica e perspectivas de integração. Holos, 2, p. 4-30, 2007.

RAMOS, M. Ensino médio integrado: ciência, trabalho e cultura na relação entre educação profissional e educação básica. In: MOLL, J. et al. Educação profissional e tecnológica no Brasil contemporâneo: desafios, tensões e possibilidades. Porto Alegre: Artmed, p. 42-57, 2010.

RAMOS, M. Concepção do ensino médio integrado. In: Seminário sobre Ensino Médio, 2008. Secretaria de Educação do Pará. 08-09 maio 2008.

SEVERO, S. A História não é "decoreba": os desafios do Ensino de História no Ensino Médio na Escola Estadual Adriano Feitosa - Tavares - PB. 2014. 62 f. Monografia (Especialização) - Curso de Fundamentos da Educação: Práticas Pedagógicas Interdisciplinares, Universidade Estadual da Paraíba, Princesa Isabel, 2014.

SHEPHERD, E.; GODWIN, J. Avaliações através do processo de aprendizagem. Questionmark Corporation, 2004. 